\title{
Qualidade pós-colheita de maracujá-amarelo em função de porta-enxertos e ambientes de cultivo
}

\author{
Silvia de Carvalho Campos Botelho*1, Dulândula Silva Miguel-Wruck', \\ Embrapa Agrossilvipastoril, Sinop, Brasil \\ ${ }^{2}$ Universidade Federal de Mato Grosso, Sinop, Brasil \\ *Autor correspondente, e-mail: silvia.campos@embrapa.br
}

Givanildo Roncatto', Suzinei Silva Oliveira', Fernando Mendes Botelho², Carmen Wobeto

\begin{abstract}
Resumo
Objetivou-se avaliar a influência de porta-enxertos e ambientes nas características físico-químicas de frutos de maracujazeiros. $O$ experimento foi instalado e conduzido em duas propriedades no município de Terra Nova do Norte, Mato Grosso. Adotou-se o esquema fatorial $2 \times 8$, no delineamento de blocos casualizados, com quatro repetições, sendo dois ambientes de produção (Ambiente 1 e Ambiente 2) e sete porta-enxertos, além da testemunha. Foram utilizados os portaenxertos dos seguintes genótipos: CPAC M5-H-67, CPAC MJ-H-65, CPAC MJ-45-03, CPAC MJ-H-68, Passiflora nitida (PN), P. alata (PA) e P. edulis (PE), sob a copa da cultivar de maracujazeiro-amarelo, BRS Gigante Amarelo (GA), e essa cultivada em pé franco como testemunha. Após a colheita, retiraram-se, aleatoriamente, dez frutos de cada bloco para a realização das seguintes análises físicas e físico-químicas: massa, comprimento e diâmetro do fruto, espessura da casca, teor de sólidos solúveis totais (SST), acidez total titulável (ATT), relação SST/ATT e teor de vitamina C. O uso dos porta-enxertos e a interação porta-enxertos $\mathrm{x}$ ambiente influenciaram as características físicas dos frutos de maracujazeiro. Os ambientes influenciaram as características físico-químicas dos frutos, exceto para a ATT. O ambiente 1 proporcionou frutos de melhor qualidade. No ambiente 2 não houve variação de massa e comprimento de frutos com o uso dos porta-enxertos. Todos os porta-enxertos analisados produziram frutos com características adequadas para consumo in natura ou para industrialização.
\end{abstract}

Palavras-chave: análises qualitativas, fusariose, Passiflora edulis

Postharvest quality of yellow passion fruit according to different rootstocks and growing environments

\begin{abstract}
The objective of this study was to evaluate the influence of rootstocks on passion fruit physicochemical characteristics. The experiment was conducted in two properties in Terra Nova do Norte municipality, Mato Grosso State, Brazil. The experiment was conducted in a $2 \times 8$ factorial, in a completely randomized block design with four repetitions, being two growing environments (Environment 1 and Environment 2) and seven rootstocks with one control. The rootstocks used were: $\mathrm{CPAC} M 5-\mathrm{H}-$ 67, H-CPAC MJ-65, CPAC MJ-45-03, CPAC MJ-H-68, Passiflora nitida (PN), P. alata (PA) and P. edulis $(\mathrm{PE})$, under the canopy of a yellow passion fruit, BRS Gigante Amarelo cultivar. The same cultivar without rootstock was used as a control. The fruits were randomly harvest from each block. The following physical, physicochemical and chemical analysis were performed: weight, fruit length and diameter of the fruit, skin thickness, total soluble solids content (TSS), total acidity (TA), TSS/TA and vitamin $C$ content. The use of rootstocks and rootstocks $x$ environment interaction influenced the passion fruit physical characteristics. The environments influenced fruit quality, except for total acidity content. Environment 1 resulted in best fruit quality. For the Environment 2 no weight and length variation caused by rootstocks was observed. All analyzed rootstocks produced fruit with suitable characteristics for 'in natura' consumption or industrialization.
\end{abstract}

Keywords: Qualitative analysis, fusariosis, Passiflora edulis 


\section{Introdução}

A produção de maracujás no Brasil é uma atividade de grande interesse em função do curto ciclo da cultura, alto retorno econômico e grande mercado consumidor, tanto para - consumo natural como industrializado, principalmente na forma de suco (Meletti, 2011). O maracujazeiro-amarelo (Passiflora edulis Sims) representa $97 \%$ da área plantada e do volume comercializado em todo país, com $60 \%$ da produção destinada ao consumo in natura e o restante destinado às indústrias de processamento (Ferraz \& Lot, 2007).

No Brasil, as doenças e as pragas são os principais fatores que ameaçam a expansão e a produtividade dos cultivos do maracujazeiros, provocando prejuízos expressivos e levando os produtores a usarem defensivos agrícolas de forma indiscriminada. Em algumas regiões do país, doenças, como a murcha de fusarium ou fusariose (Fusarium oxysporum f.sp. passiflorae), têm sido limitante a esta expansão, sendo responsável pela redução de área plantada e pelo caráter itinerante da cultura (Cavichioli et al., $2011 \mathrm{~b})$.

Em condições edafoclimáticas favoráveis, essa doença não pode ser controlada de forma eficaz pelos métodos tradicionais de controle (Junqueira et al., 2005) devendo utilizar-se de medidas preventivas para o seu controle, tais como: evitar o plantio em solos pesados e compactados, utilizar mudas sadias e evitar ferimentos no colo e nas raízes das plantas (Cavichioli et al., 2011 b). Além disso, outra alternativa, como medida preventiva, pode ser o uso de porta-enxertos de genótipos tolerantes à fusariose. A murcha por fusarium leva à leve clorose das folhas e murcha desigual da parte aérea. Depois os sintomas tornam-se mais graves, quando as folhas caem levando a planta à morte (Ploetz, 2006).

A enxertia no maracujazeiro tem sido descrita por diversos autores (Cavichioli et al., 2009), sendo que a utilização de porta-enxertos tolerantes à doenças pode ser uma forma de viabilizar o plantio de maracujazeiros em áreas com histórico de ocorrência de doenças (Braga et al., 2006). Entretanto, as razões pelas quais se realiza a enxertia, como redução do período juvenil, com maior precocidade de produção, redução do porte da planta e propagação de genótipos selecionados, não tem justificado a enxertia em maracujazeiro (Morgado et al., 2015).

A enxertia do maracujá-amarelo sobre outras espécies não cultivadas, visando ao controle da fusariose é uma realidade, sendo a enxertia hipocotiledonar a mais indicada, uma vez que para as regiões afetadas por patógenos de solo, plantas enxertadas tornam o cultivo possível (Meletti, 2011). Tem-se estudado aspectos relativos à produção de mudas enxertadas, compatibilidade entre enxerto e porta-enxerto e sobrevivência de plantas no campo com resultados satisfatórios (Nogueira Filho et al., 201 1; Roncatto et al., 2011 la e 2011 b; Lenza et al., 2009).

Apesar disso, poucos trabalhos se propuseram a avaliar as alterações nas características dos frutos produzidos por mudas enxertadas, podendo ser citados os estudos realizados por Nogueira Filho et al. (2010); Cavichioli et al. (2011a); Junqueira et al. (2006). Os resultados, entretanto, são controversos.

Desta forma, objetivou-se com este trabalho avaliar a influência de porta-enxertos em dois ambientes nas características físicas e físico-químicas de frutos de maracujazeiroamarelo.

\section{Material e Métodos}

O experimento foi conduzido em dois ambientes no município de Terra Nova do Norte (10³1' S, 5513' W e altitude média de $250 \mathrm{~m}$ ), Mato Grosso. Ambos ambientes localizam-se sob as mesmas condições climáticas, sendo o clima da região é do tipo Aw, com chuvas concentradas no verão e inverno seco, médias de temperatura máxima de $32,6^{\circ} \mathrm{C}$ e mínima de $20,7^{\circ} \mathrm{C}$, precipitação anual de $2.513,4 \mathrm{~mm}$ e umidade relativa do ar anual média de $77,7 \%$. Os ambientes distam entre si, aproximadamente, $2.500 \mathrm{~m}$.

Adotou-se um esquema fatorial $2 \times 8$, sendo dois ambientes e oito tratamentos (sete porta-enxertos e um pé-franco), em um delineamento de blocos casualizados, com quatro repetições e seis plantas por parcela 
(sendo quatro plantas úteis), em espaçamento $3 \times 3 \mathrm{~m}$. Os porta-enxertos avaliados foram os híbridos CPAC M5-H-67, CPAC MJ-H-65, CPAC MJ-45-03, CPAC MJ-H-68, além de Passifora nitida (PN), P. alata (PA) e P. edulis (PE). A cultivar BRS Gigante Amarelo (GA) (P. edulis) foi cultivada em pé-franco para ser comparada como testemunha e compôs a copa de todos os porta-enxertos.

A análise química do solo apresentou os seguintes valores: Ambiente 1 - $\mathrm{Al}\left(0,00 \mathrm{cmol}_{\mathrm{C}} \mathrm{dm}^{-}\right.$ 3); $\mathrm{Ca}+\mathrm{Mg}\left(2,1 \mathrm{cmol}_{\mathrm{C}} \mathrm{dm}^{-3}\right) ; \mathrm{P}\left(3,9 \mathrm{mg} \mathrm{dm}^{-3}\right) ; \mathrm{K}(62$ mg dm³); pH (água) 5,6, e saturação por Al 0\%; Ambiente 2 - Al $\left(0,00 \mathrm{cmol}_{\mathrm{c}} \mathrm{dm}^{-3}\right) ; \mathrm{Ca}+\mathrm{Mg}(2,7$ $\left.\mathrm{cmol}_{\mathrm{c}} \mathrm{dm}^{-3}\right) ; \mathrm{P}\left(3,3 \mathrm{mg} \mathrm{dm}^{-3}\right) ; \mathrm{K}\left(45 \mathrm{mg} \mathrm{dm}^{-3}\right) ; \mathrm{pH}$ (água) 5,8, e saturação por Al 0\%. Foram abertas covas de dimensões $40 \times 40 \times 40 \mathrm{~cm}$ e utilizaramse $5 \mathrm{~L}$ de cama de frango, $200 \mathrm{~g}$ de calcário e $100 \mathrm{~g}$ de fosfato monoamônico (MAP) por cova, que misturadas ao solo, perfizeram a adubação de implantação, conforme análise de solo e recomendação de Borges (2004). Os tratos culturais e controle de pragas e doenças foram conduzidos conforme o realizado normalmente para a cultura (Lima \& Borges, 2005).

As mudas do enxerto e dos portaenxertos foram produzidas em tubetes de 288 $\mathrm{cm}^{3}$, com substrato composto por mistura de solo, esterco de curral curtido e substrato comercial Plantmax ${ }^{\otimes}$ (à base de casca de pinus), na proporção 3:1:1. Quando as mudas atingiram de 6 a $8 \mathrm{~cm}$ de altura, com três folhas trilobadas realizou-se a enxertia em fenda cheia no topo logo acima dos cotilédones utilizandose o método descrito por Nogueira Filho et al. (2010).

Os ensaios foram instalados em setembro (ambiente 1) e outubro (ambiente 2) de 2012, quando as mudas enxertadas apresentavam entre 90 e 120 dias, após a enxertia. A irrigação foi realizada por gotejamento, entre os meses de junho e agosto de 2013. O sistema de condução da lavoura foi por espaldeira, com os mourões a uma distância de $5 \mathrm{~m}$ e um fio de arame liso a $1,8 \mathrm{~m}$ de altura em relação ao solo. As plantas foram conduzidas com auxílio de barbante em haste única até atingir a altura do fio de arame e direcionadas para um dos lados da espaldeira. Foi retirada a gema apical do ramo principal ao atingir a planta vizinha, para formação da cortina lateral. A polinização foi manual e realizada após a abertura das flores, normalmente após as $13 \mathrm{~h}$.

Sete meses após o transplantio das mudas, todas as plantas já apresentavam produção de frutos. Assim, os frutos que já se encontravam no chão foram retirados de forma a limpar a área de produção. Após esta limpeza, aguardaram-se cinco dias e procedeu-se à colheita dos frutos para análises. A colheita foi realizada em um mesmo dia, de forma aleatória, sendo colhidos do chão os frutos com casca totalmente amarela.

Para as avaliações, retirou-se, em cada parcela experimental, uma amostra de 10 frutos, num total de 320 frutos, por ambiente. Os frutos foram transportados em caixas plásticas até a Embrapa Agrossilvipastoril (Sinop-MT), onde foram realizadas as análises, exceto de vitamina C, que foi realizada no Laboratório de Tecnologia de Alimentos da UFMT/Campus Sinop.

A massa dos frutos foi obtida com uso de balança analítica com resolução de 0,01 g. O comprimento e o diâmetro dos frutos e a espessura das cascas foram medidos com paquímetro digital com resolução de 0,1 $\mathrm{mm}$. O teor de sólidos solúveis totais (SST) foi obtido por meio de um refratômetro digital portátil marca Atago, modelo PAL-1 com compensação automática de temperatura. A acidez total titulável (ATT) foi determinada por titulometria, com $\mathrm{NaOH}$ a $0,1 \mathrm{~mol} \mathrm{~L}^{-1}$, expressa em porcentagem de ácido cítrico (AOAC, 1990). Em seguida, determinou-se a relação SST/ATT. O teor de vitamina $C$ total da polpa foi determinado por método espectrofotométrico (Stroehecker \& Henning, 1967).

\section{Análise estatística}

Para cada característica foi realizada análise de variância conjunta, ou seja, considerando-se os dois ambientes. Para as características que demonstraram a ocorrência de interação entre porta-enxerto e ambiente foi realizado o desdobramento da interação, avaliando-se os porta-enxertos dentro de cada local. Os dados obtidos foram analisados utilizando-se os recursos computacionais do programa GENES (Cruz, 2013). 
As características mensuradas foram submetidas a uma análise de variância, conforme o delineamento em blocos ao acaso, com quatro repetições, em dois ambientes, de acordo com o modelo estatístico:

$$
Y_{i j k}=\mu+P_{i}+B / A_{j k}+A_{j}+P A_{i j}+e_{i j k}
$$

em que: $Y_{i j k}$ : observação da característica no k-ésimo bloco, avaliada dentro do j-ésimo ambiente no i-ésimo porta-enxerto; $\mu$ : média geral; $P_{i}$ : efeito do i-ésimo porta-enxerto considerado fixo; $A_{j}$ : efeito do j-ésimo ambiente, considerado fixo; $P A_{i j}$ : efeito da interação entre o i-ésimo porta-enxerto e o j-ésimo ambiente, considerado fixo; $B / A_{j k}$ : efeito do k-ésimo bloco dentro do j-ésimo ambiente, considerado aleatório; e $e_{i j k}$ : efeito do erro experimental associado à observação de ordem ijk, considerado aleatório.

Os dados da variável "vitamina C" não atenderam aos requisitos de homocedasticidade das variâncias. Desta forma, foi realizada análise individual, por ambiente para esta característica.

\section{Resultados e Discussão}

A ocorrência de interação significativa entre porta-enxertos (P) e ambiente (A) para massa de frutos (MF) e comprimento de frutos (CF) evidenciou que os porta-enxertos avaliados não mantiveram a mesma equivalência em ambos os ambientes, quanto ao tamanho dos frutos. Para a característica diâmetro do fruto (DF) não houve interação significativa, mas verificou-se diferença significativa entre ambientes e entre porta-enxertos (Tabela 1).

Tabela 1. Quadrado médio de massa (MF), comprimento (CF), diâmetro (DF), espessura da casca (EC), sólidos solúveis totais (SST), acidez total titulável (ATT) e ratio (RT) de frutos de maracujazeiro-amarelo produzidos com sete porta-enxertos e pé-franco em dois ambientes, em 2013

\begin{tabular}{|c|c|c|c|c|c|c|c|c|}
\hline \multirow{2}{*}{ Fonte de variação } & \multirow{2}{*}{ GL } & \multicolumn{7}{|c|}{ Quadrado Médio } \\
\hline & & $M F(g)$ & $\mathrm{CF}(\mathrm{mm})$ & $\mathrm{DF}(\mathrm{mm})$ & $\begin{array}{c}E C \\
(\mathrm{~mm})\end{array}$ & $\begin{array}{c}\text { SST } \\
\text { ( }{ }^{\circ} \text { Brix) }\end{array}$ & ATT (\%) & RT \\
\hline Porta-enxerto (P) & 7 & $8946,20^{* *}$ & $111,27^{* *}$ & $86,83^{*}$ & $0,54^{\text {ns }}$ & $1,29^{\text {ns }}$ & $0,15^{\text {ns }}$ & $0,46^{\mathrm{ns}}$ \\
\hline Ambiente (A) & 1 & $284382,61^{* *}$ & $1911,27^{* *}$ & $2323,14^{* *}$ & $385,37^{* *}$ & $25,64^{* *}$ & $0,07^{n s}$ & $4,51^{* *}$ \\
\hline$P \times A$ & 7 & $5960,52^{* *}$ & $85,38^{* *}$ & $46,12^{\text {ns }}$ & $0,64^{\mathrm{ns}}$ & $0,41^{\mathrm{ns}}$ & $0,25^{\text {ns }}$ & $0,45^{\text {ns }}$ \\
\hline $\mathrm{P} / \mathrm{A}$ & 14 & $7453,36^{* *}$ & $98,33^{* *}$ & - & - & - & - & - \\
\hline $\mathrm{P} / \mathrm{Al}$ & 7 & $14466,72^{* *}$ & $173,55^{* *}$ & - & - & - & - & - \\
\hline P/A2 & 7 & $439,99^{\text {ns }}$ & $23,10^{\text {ns }}$ & - & - & - & - & - \\
\hline Resíduo & 42 & 932,08 & 22,20 & 29,29 & 0,91 & 0,95 & 0,21 & 0,43 \\
\hline CV (\%) & & 14,32 & 4,83 & 6,53 & 14,25 & 7,70 & 13,95 & 16,52 \\
\hline Média Geral & & 213,15 & 97,44 & 79,82 & 6,65 & 12,65 & 3,25 & 3,95 \\
\hline Média A 1 & & 279,81 & 102,91 & 82,84 & 9,10 & 13,30 & 3,22 & 4,22 \\
\hline Média A2 & & 146,49 & 91,96 & 76,79 & 4,20 & 12,00 & 3,29 & 3,69 \\
\hline
\end{tabular}

Quando avaliados espessura da casca (EC), teor de sólidos solúveis totais (SST) e ratio (RT) foi observada diferença significativa entre os ambientes, mas não entre os porta-enxertos. Para acidez total titulável (ATT) não houve diferença significativa entre os ambientes ou entre os porta-enxertos (Tabela 1).

Verificou-se que a média dos valores do Ambiente 1 foi superior à do ambiente 2 para todas as características observadas (Tabela 1), exceto para ATT. É possível que este resultado tenha sido obtido em função da diferença nos tratos culturais aplicados em cada pomar, uma vez que foi verificado que o controle de doenças e pragas no Ambiente 2 não foi realizado em tempo adequado e houve interrupção da irrigação do pomar, durante o período de seca,
- que pode ter contribuído para a redução na qualidade dos frutos.

Observou-se, no Ambiente 1 (Tabela 2), que os porta-enxertos PE (Passiflora edulis) e CPAC MJ-45-03 não diferiram entre si e se destacaram com frutos de maior massa $(395,9$ $\mathrm{g}$ e 330,6 g, respectivamente). Junqueira et al. (2006) obtiveram frutos mais pesados $(152,46$ g) ao enxertar o maracujá-amarelo no portaenxerto da espécie Passiflora nitida em relação ao pé franco $(123,98 \mathrm{~g})$.

Os porta-enxertos PA, CPAC MJ-H-68, CPAC MJ-H-65, CPAC M5-H-67 e a testemunha GA apresentaram menor massa de frutos, porém, acima da exigência para o mercado in natura, uma vez que Freitas et al. (2011) destacaram que frutos com massa média acima 
de $180 \mathrm{~g}$ apresentam ótimo valor comercial para consumo in natura.

Tabela 2. Média da massa $(\mathrm{g})$ e do comprimento $(\mathrm{mm})$ de frutos de maracujazeiro-amarelo produzidos com sete porta-enxertos e pé-franco em dois ambientes, em 2013

\begin{tabular}{|c|c|c|c|c|c|c|c|}
\hline \multirow{3}{*}{$\begin{array}{l}\text { Porta-enxerto } \\
\text { GA }\end{array}$} & \multicolumn{3}{|c|}{ Massa (a) } & \multicolumn{4}{|c|}{ Comprimento (mm) } \\
\hline & \multicolumn{2}{|c|}{ Ambiente 1} & Ambiente 2 & \multicolumn{2}{|c|}{ Ambiente 1} & \multicolumn{2}{|l|}{ Ambiente 2} \\
\hline & 279,1 & $\mathrm{bcd}^{2}$ & 161,8 ns & 105,4 & $a b^{2}$ & 91,9 & ns \\
\hline CPAC M5-H-67 & 216,9 & $d$ & 130,0 & 98,2 & $\mathrm{bc}$ & 88,0 & \\
\hline CPAC MJ-H-65 & 253,1 & $\mathrm{~cd}$ & 134,9 & 105,7 & $a b$ & 88,8 & \\
\hline CPAC MJ-45-03 & 330,6 & $a b$ & 154,8 & 109,2 & $a$ & 93,7 & \\
\hline CPAC MJ-H-68 & 251,7 & $\mathrm{~cd}$ & 149,4 & 97,2 & $\mathrm{bc}$ & 94,5 & \\
\hline PA & 219,3 & d & 142,7 & 91,5 & c & 91,7 & \\
\hline PE & 395,9 & $a$ & 152,7 & 110,4 & $a$ & 93,2 & \\
\hline $\mathrm{PN}$ & 291,8 & $b c$ & 145,5 & 105,7 & $a b$ & 93,9 & \\
\hline Média & $272,5 \mathrm{~A}^{1}$ & & $147,0 \mathrm{~B}$ & $102,9 \mathrm{~A}^{1}$ & & $92,0 \mathrm{~B}$ & \\
\hline
\end{tabular}

No Ambiente 2 não houve diferença entre os porta-enxertos na massa de frutos, cuja média obtida foi de $147 \mathrm{~g}$.

Zaccheo et al. (2012), avaliando híbridos de maracujazeiros no interior do Paraná, verificaram que a maior média de massa dos frutos foi de 199 a $205 \mathrm{~g}$, inferior ao observado neste trabalho, no ambiente 1. Em Adamantina, interior de São Paulo, Cavichioli et al. (2014) observaram massa média de frutos variando entre 127,77 e 201,03 g, também inferiores aos observados neste trabalho no Ambiente 1. Maia et al. (2009) obtiveram massa média de frutos de maracujazeiros entre 103 e 173g.

Em relação ao comprimento dos frutos, os porta-enxertos CPAC MJ-45-03, PE, GA, CPAC MJ-H-65 e PN resultaram em maiores médias, não diferindo entre si. As menores médias de comprimento de fruto foram obtidas utilizandose PA, CPAC M5-H-67 e CPAC MJ-H-68. Cavichioli et al. (2011b) observaram frutos maiores (comprimento e diâmetro) em plantas de péfranco quando comparados com as enxertadas em $P$. alata e $P$. gibertii.

A média do diâmetro dos frutos produzidos no ambiente 1 foi de $82,8 \mathrm{~mm}$ superando os $76,8 \mathrm{~mm}$ do ambiente 2 (Tabela 3 ), variando de $83,4 \mathrm{~mm}$ para PE a $74,9 \mathrm{~mm}$ para CPAC M5-H-67. Frutos menores produzidos no ambiente 2 podem ter sido devido ao manejo, conforme já relatado. Também Fisher et al. (2007) observaram diferenças no diâmetro dos fruto quanto ao sistema de manejo, obtendo diâmetro médio de $63,70 \mathrm{~mm}$ para frutos em cultivo convencional e $76,30 \mathrm{~mm}$ para frutos $\mathrm{em}$ cultivo orgânico.

Tabela 3. Média do diâmetro $(\mathrm{mm})$ de frutos de maracujazeiro-amarelo produzidos com sete porta-enxertos e pé-franco em dois ambientes, em 2013

\begin{tabular}{lccc}
\hline Porta-enxerto & Ambiente 1 & Ambiente 2 & Média \\
\hline GA & 84,1 & 79,5 & $81,8 \mathrm{ab}^{2}$ \\
CPAC M5-H-67 & 77,3 & 72,6 & $74,9 \mathrm{~b}$ \\
CPAC MJ-H-65 & 81,1 & 76,9 & $79,0 \mathrm{ab}$ \\
CPAC MJ-45-03 & 83,0 & 76,4 & $79,7 \mathrm{ab}$ \\
CPAC MJ-H-68 & 82,2 & 76,8 & $79,5 \mathrm{ab}$ \\
PA & 82,8 & 78,0 & $80,4 \mathrm{ab}$ \\
PE & 89,2 & 77,6 & $83,4 \mathrm{a}$ \\
PN & 82,9 & 76,5 & $79,7 \mathrm{ab}$ \\
\hline Média & $82,8 \mathrm{~A}^{1}$ & $76,8 \mathrm{~B}$ & \\
\hline 'Médias seguidas pelas mesmas letras maiúsculas na horizontal não diferem estatisticamente entre si pelo teste F; ${ }^{2}$ Médias seguidas pelas mesmas letras minúscula na \\
vertical não diferem estatisticamente entre si pelo teste de Tukey a 5\% de probabilidade.
\end{tabular}

Comparando-se estes resultados com os obtidos por Abreu et al. (2009), que avaliaram a qualidade de cinco genótipos de maracujá azedo no Distrito Federal, dentre estes o Gigante Amarelo, observou-se a massa fresca, comprimento, diâmetro e espessura da casca 
dos frutos, deste genótipo (denominado PA neste trabalho) foi, respectivamente, de 129,45 $\mathrm{g}, 82,8 \mathrm{~mm}, 69,6 \mathrm{~mm}$ e $5,17 \mathrm{~mm}$. Verificam-se que os níveis destes parâmetros nos ambientes 1 e 2 foram, em valores absolutos, superiores aos cultivados no Distrito Federal.

A média da espessura de casca dos frutos produzidos foi maior no ambiente $1 \quad(9,1$ $\mathrm{mm}$ ) do que no ambiente 2 (4,2 $\mathrm{mm}$ ) (Tabela 1), não diferindo entre os porta-enxertos e o pé franco. Cavichioli et al. (201 la) não obtiveram diferenças de espessura da casca de frutos de maracujazeiro-amarelo em diferentes portaenxertos, mas estes diferiram do pé franco 19,72 $\mathrm{mm}$ ). Negreiros et al. (2007) observaram que a espessura da casca apresentou efeito direto elevado, porém negativo sobre o rendimento de polpa. Assim, a espessura da casca influencia diretamente na queda do rendimento de polpa quando estas são muito espessas.

O teor médio de sólidos solúveis totais no Ambiente 1 foi de $13,3{ }^{\circ}$ Brix, sendo superior aos 12,0 ${ }^{\circ}$ Brix obtidos no ambiente 2 (Tabela 1 ). Esses valores foram superiores aos verificados por Junqueira et al. (2006) cujos resultados foram de 10,8 ${ }^{\circ}$ Brix em frutos de maracujazeiro-amarelo provenientes de pé franco e 11,7ºrix em frutos de plantas enxertadas em Passiflora nitida. Os teores de sólidos solúveis totais indicam a quantidade de sólidos dissolvidos na polpa, sendo $13^{\circ}$ Brix o padrão mínimo exigido por indústrias de suco.

Segundo Chitarra \& Chitarra (2005), as matérias primas são tanto melhores para a industrialização quanto maiores forem seus teores de açúcar e, portanto, de sólidos solúveis. Desta forma, observa-se que o manejo do pomar do ambiente 2 pode ter prejudicado, além das características físicas dos frutos, gerando frutos menores, a constituição dos mesmos, como a síntese de sólidos solúveis. Estes mesmos autores destacam ainda que as variações de SST numa mesma espécie são decorrentes de fatores diversos como cultivares, tipo de solo, condições climáticas e práticas culturais.

Não houve diferença na acidez total titulável entre os ambientes ou entre os portaenxertos, tendo-se obtido a acidez média de 3,25\% (Tabela 1). O Ministério da Agricultura, Pecuária e Abastecimento recomenda um valor mínimo de 2,5\% de ATT no suco de maracujá (Brasil, 2003), confirmando a região norte de Mato Grosso interessante para a industrialização do maracujá como suco. Outros autores, entretanto, encontraram valores superiores aos vistos neste trabalho, como Aguiar et al. (2015) que obtiveram valores de ATT variando de 3,7 a 5,0\% no Paraná; Cavichioli et al. (2011a) que observaram variações entre 3,9 e 4,4\% quando avaliaram três porta-enxertos, entre eles $O P$. alata e $\circ$ P. edulis, sendo a copa $\circ$ P. edulis, como neste trabalho; e, Solino et al. (2012) que verificaram valores de ATT entre 4,18 e 5,39\%.

A razão SST/ATT foi de 4,22 para 0 Ambiente 1 e 3,70 para o Ambiente 2 (Tabela 1). Zaccheo et al. (2012) observaram valores de ratio entre 4,3 e 2,6 e Aguiar et al. (2015) valores variando entre 2,95 e 4,0. A relação SST/ ATT é uma das formas mais utilizadas para a avaliação do sabor, sendo mais representativa que a medição isolada de açúcares ou acidez (Chitarra \& Chitarra, 2005).

O teor de vitamina $C$ obteve o valor de 23,19 na relação entre o maior e o menor quadrado médio de resíduo dentro de ambiente sendo este muito superior ao limite preconizado por Gomes \& Garcia (2002) para possibilidade de análise de variância conjunta. Desta forma, o resultado do teste de médias entre os portaenxertos, dentro de cada ambiente, encontra-se na Tabela 4.

Observou-se que os frutos, cultivados no Ambiente 1, no porta-enxerto CPAC MJ-H-68 apresentaram o teor de vitamina C mais elevado $\left(55,81 \mathrm{mg}^{\left.100 \mathrm{~g}^{-1}\right)}\right.$ e significativamente superior aos dos frutos cultivados em pé-franco (GA).

No Ambiente 2, os frutos do portaenxerto PN destacaram-se como os de maiores teores de vitamina $C\left(19,31 \mathrm{mg} 100 \mathrm{~g}^{-1}\right)$. Porém, no Ambiente 2, somente os porta-enxertos CPAC M5-H-67, CPAC MJ-H-68 e PA diferiram estatisticamente de PN. Constatou-se que, além dos porta-enxertos, outras variáveis não controladas, como por exemplo o manejo, possivelmente afetaram os níveis dessa vitamina nos frutos, e que, de um modo geral, os frutos do Ambiente 1 novamente apresentaram maiores teores também para este parâmetro.

Outros estudos já demonstraram que 
vários fatores podem afetar os teores de vitamina C nos frutos, dentre estes, o estágio de maturação (Coelho et al., 2010) e o tipo de cultivo (Pertuzatti et al., 2015).

Apesar da diferença nos teores de vitamina $\mathrm{C}$ encontrados neste estudo entre os ambientes, os valores obtidos corroboram com a faixa de variação de, 13,0 a 64,8 mg $100 \mathrm{~g}^{-1}$, relatada em vários estudos com maracujáamarelo (Farias et al., 2007; Coelho et al., 2010; Cerqueira et al., 2011).

Tabela 4. Médias do teor de vitamina $C\left(\mathrm{mg} 100 \mathrm{~g}^{-1}\right)$ de frutos de maracujazeiro-amarelo produzidos em dois ambientes, em 2013

\begin{tabular}{|c|c|c|c|c|}
\hline Porta enxerto & \multicolumn{2}{|c|}{ Ambiente 1} & \multicolumn{2}{|c|}{ Ambiente 2} \\
\hline GA & 37,83 & $a b^{\prime}$ & 16,72 & $a b$ \\
\hline CPAC M5-H-67 & 41,09 & $a b c$ & 14,05 & $a$ \\
\hline CPAC MJ-H-65 & 37,89 & $a b$ & 15,72 & $a b$ \\
\hline CPAC MJ-45-03 & 32,99 & a & 17,30 & $a b$ \\
\hline CPAC MJ-H-68 & 55,81 & c & 14,14 & $a$ \\
\hline PA & 50,38 & $\mathrm{bc}$ & 15,06 & $a$ \\
\hline PE & 49,55 & bc & 17,61 & $a b$ \\
\hline PN & 50,83 & $\mathrm{bc}$ & 19,31 & $b$ \\
\hline CV (\%) & \multicolumn{2}{|c|}{15,78} & \multicolumn{2}{|c|}{10,70} \\
\hline
\end{tabular}

\section{Conclusões}

O uso dos porta-enxertos e a interação porta-enxertos $x$ ambiente influenciam as características físicas dos frutos de maracujazeiro.

De modo geral, o conjunto portaenxerto CPAC MJ-45-03/BRS Gigante Amarelo foi que apresentou frutos de melhor qualidade.

O ambiente de produção influencia qualidade de frutos, exceto a ATT, sendo o Ambiente 1 o melhor para qualidade dos frutos.

\section{Agradecimentos}

À Fundação de Amparo à Pesquisa do Estado de Mato Grosso - Fapemat, pelo auxílio financeiro.

\section{Referências}

Abreu, S.P.M., Peixoto, J.R., Junqueira, N.T.V., Sousa, M.A.F. 2009. Características físico-químicas de cinco genótipos de maracujazeiro-azedo cultivados no Distrito Federal. Revista Brasileira de Fruticultura 31: 487-491.

Aguiar, R.S., Zaccheo, P.V.C., Stenzel, N.M.C., Sera, T., Neves, C.S.V. 2015. Produção e qualidade de frutos híbridos de maracujazeiroamarelo no norte do Paraná. Revista Brasileira de Fruticultura 37: 130-137.

AOAC - Association of Official Analytical Chemists. 1990. Official methods of analysis of the Association of Official Analytical Chemists. Arlington, VA, USA. $1017 \mathrm{p}$

Borges, A.L. 2004. Nutrição mineral, calagem e adubação. In.: Lima, A.A., Cunha, M.A.P. (ed.). Maracujá: produção e qualidade na passicultura. Embrapa Mandioca e Fruticultura, Cruz das Almas, Brasil. p. 117-149.

Braga, M.F., Santos, E.C., Junqueira, N.T.V., Sousa, A.A.T.C., Faleiro, F.G., Rezende, L.N., Junqueira, K.P. 2006. Enraizamento de estacas de três espécies silvestres de Passiflora. Revista Brasileira de Fruticultura 28: 284-288.

Brasil. 2003. Ministério da Agricultura e do Abastecimento. Instrução Normativa $n^{\circ} 12$, de 4 de setembro de 2003. Diário Oficial da União 1: 72-76.

Cavichioli, J.C., Corrêa, L.S., Boliani, A.C., Oliveira, J.C. 2009. Uso de câmara úmida em enxertia hipocotiledonar de maracujazeiro-amarelo sobre três porta-enxertos. Revista Brasileira de Fruticultura 31: 532-538.

Cavichioli, J.C., Corrêa, L.S., Boliani, A.C., Santos, P.C. 2011 a. Características físicas e químicas de frutos de maracujazeiro-amarelo enxertado em três porta-enxertos. Revista Brasileira de Fruticultura 33: 906-914.

Cavichioli, J.C., Correa, L.S., Garcia, M.J.M., Fischer, I.H. $2011 \mathrm{~b}$. Desenvolvimento, produtividade e sobrevivência de maracujazeiroamarelo enxertado e cultivado em área com histórico de morte prematura de plantas. Revista Brasileira de Fruticultura 33: 567-574.

Cavichioli, J.C., Kasai, F.S., Nasser, M.D. 2014. Produtividade e características físicas de frutos de Passiflora edulis enxertado sobre Passiflora gibertii em diferentes espaçamentos de plantio. Revista Brasileira de Fruticultura 36: 243-247. 
Cerqueira, F.O.S., Resende, E.D., Martins, D.R., Santos, J.L.V., Cenci, S.A. 2011. Quality of yellow passion fruit stored under refrigeration and controlled atmosphere. Ciência e Tecnologia de Alimentos 31: 534-540.

Chitarra, M.I.F., Chitarra, A.B. 2005. Pós-colheita de frutas e hortaliças: fisiologia e manuseio. UFLA, Lavras, Brasil. 783 p.

Coelho, A.A., Cenci, S.A., Resende, E.D. 2010. Qualidade do suco de maracujá-amarelo em diferentes pontos de colheita e após 0 amadurecimento. Ciência e Agrotecnologia 34: 722-729.

Cruz, C.D. 2013. GENES: a software package for analysis in experimental statistics and quantitative genetics. Acta Scientiarum. Agronomy 35: 271276.

Farias, J.F., Silva, J.B.L., Araújo Neto, S.E., Mendonça, V. 2007. Qualidade do maracujáamarelo comercializado em Rio Branco, Acre. Caatinga 20: 196-202.

Ferraz, J.V., Lot, L. 2007. Fruta para consumo in natura tem boa perspectiva de renda. In: Agrianual 2007: anuário da agricultura brasileira. Maracujá. FNP Consultoria e Comércio São Paulo, Brasil. p. 387-388.

Fischer, I.H., Arruda, M.C., Almeida, A.M., Garcia, M.J.M., Jeronimo, E.M., Pinotti, R.N., Bertani, R.M.A. 2007. Doenças e características físicas e químicas pós-colheita em maracujá-amarelo de cultivo convencional e orgânico no centro oeste paulista. Revista Brasileira de Fruticultura 29: 254 259.

Freitas, J.P.X., Oliveira, E.J., Cruz Neto, A.J., Santo S.L.R. 2011 . Avaliação de recursos genéticos de maracujazeiro-amarelo. Pesquisa Agropecuária Brasileira 46: 1013-1020.

Gomes F.P., Garcia, C.H. 2002. Estatística Aplicada a Experimentos Agronômicos e Florestais: exposição com exemplos e orientações para uso de aplicativos. ESALQ, Piracicaba, Brasil. 309 p.

Junqueira, N.T.V., Braga, M.F., Faleiro, F.G., Peixoto, J.R., Bernacci, L.C. Potencial de espécies silvestres de maracujazeiro como fonte de resistência a doenças. 2005. In: Faleiro, F.G., Junqueira, N.T.V., Braga, M.F. Maracujá: germoplasma e melhoramento genético. Embrapa Cerrados, Planaltina, Brasil. p. 81-108.

Junqueira, N.T.V., Lage, D.A.C., Braga, M.F., Peixoto, J.R., Borges, T.A., Andrade, S.R.M. 2006. Reação a doenças e produtividade de um clone de maracujazeiro-azedo propagado por estaquia e enxertia em estacas herbáceas de passiflora silvestre. Revista Brasileira de Fruticultura
28: $97-100$

Lenza, J.B., Valente, J.P., Roncatto, G., Abreu, J.A. 2009. Desenvolvimento de mudas de maracujazeiro propagadas por enxertia. Revista Brasileira de Fruticultura 31: 1135-1140.

Lima, A.A., Borges, A.L. Exigências edafoclimáticas. 2005. In: Faleiro, F.G., Junqueira, N.T.V., Braga, M.F. (Eds.) Maracujá: germoplasma e melhoramento genético. Embrapa Cerrados, Planaltina, Brasil. p.39-44.

Maia, T.E.G., Peixoto, J.R., Junqueira, N.T.V., Sousa, M.A.F. 2009. Desempenho agronômico de genótipos de maracujazeiro-azedo cultivados no Distrito Federal. Revista Brasileira de Fruticultura 31: 500-506.

Meletti, L.M.M. 2011. Avanços na cultura do maracujá no Brasil. Revista Brasileira de Fruticultura, Especial: 83-091.

Morgado, M.A.D'O., Bruckner, C.H., Rosado, L.D.S., Santos, C.E.M. 2015. Desenvolvimento de mudas de maracujazeiro-azedo enxertadas em espécies silvestres de Passiflora. Revista Brasileira de Fruticultura 37: 471-479.

Negreiros, J. R. da S., Álvares, V. S., Bruckner, C.H., Morgado, M. A.D'O., Cruz, C. D. 2007. Relação entre características físicas e o rendimento de polpa de maracujá-amarelo. Revista Brasileira de Fruticultura 29: 546-549.

Nogueira Filho, G.C., Roncatto, G., Ruggiero, C., Oliveira, J.C., Malheiros, E.B., Damião Filho, C.F. 2010. Aspectos histológicos da união da enxertia hipocotiledonar no maracujazeiro-amarelo. Revista Brasileira de Fruticultura 32: 515-521.

Nogueira Filho, G.C., Roncatto, G., Ruggiero, C., Oliveira, J.C., Malheiros, E.B. 2011. Produção de mudas de maracujazeiro-amarelo por enxertia hipocotiledonar sobre sete espécies de passifloras. Revista Brasileira de Fruticultura 33: 237-245.

Pertuzatti, P.B., Sganzerla, M., Jacques, A.C., Barcia, M.T., Zambiazi, R.C. 2015. Carotenoids, tocopherols and ascorbic acid content in yellow passion fruit (Passiflora edulis) grown under different cultivation systems. Food Science and Technology 64: 259-263.

Ploetz, R.C. 2006. Fusarium-Induced Diseases of Tropical, Perennial Crops. Phytopathology 96: 648-652.

Roncatto, G., Assis, G.M.L., Oliveira, T.K., Lessa, L.S. 2011 a. Aspectos vegetativos de combinações copa/porta-enxerto em maracujazeiro. Revista Brasileira de Fruticultura 33: 791-797.

Roncatto, G., Assis, G.M.L., Oliveira, T.K., Lessa, 
L.S. 201 1b. Pegamento da enxertia em diferentes combinações de variedades e espécies utilizadas como copa e como porta-enxertos de maracujazeiro. Revista Brasileira de Fruticultura 33: 948-953.

Solino, A.J.S., Araujo Neto, S.E., Silva, A.N., Ribeiro, A.M.A.S. 2012. Severidade da antracnose e qualidade dos frutos de maracujá-amarelo tratados com produtos naturais em pós-colheita. Revista Brasileira de Fruticultura 34: 057-066.

Stroehecker, R., Henning, H.M. 1967. Análises de vitaminas: métodos comprovados. Paz Montalvo, Madrid, Espanha. 428 p.

Zaccheo, P.V.C., Aguiar, R.S., Stenzel, N.M.C., Sera, T, Neves, C.S.V.J. 2012. Produção e características qualitativas dos frutos de híbridos de maracujazeiro-amarelo. Revista Brasileira de Fruticultura 34: $1113-1120$. 